\title{
Patentability in Europe
}

\author{
Colm Murphy
}

Today, protecting your invention requires an understanding of patent systems worldwide. In this, the first article of the Nature Reviews

Drug Discovery Patent Guide, what can and cannot be patented is explored in the context of the European legislative framework. In Europe, for an invention to be patentable it must be capable of industrial application, be new and not obvious in view of the existing knowledge.

The claims of a patent define the scope of protection for an invention, and accordingly they are assessed in light of the existing knowledge to consider whether the invention complies with the requirements for patentability. Claims generally fall into two categories: the first referring to a physical entity, such as a product or apparatus; the second, to a process or use. It is permitted to use one or more categories of claim so as to adequately protect an invention provided that both claim types embody the same inventive concept. Within these categories are various sub categories where the claim will be defined in terms of its technical content in the context of a particular field or area of interest, such as, for example, a pharmaceutical composition having a defined structure. Similarly, if a new use has been identified for the pharmaceutical compound it is possible to claim that new use.

\section{Exclusions}

For an invention to be patentable in Europe it must possess a technical character, and the European Patent Convention (EPC) lists examples of those inventions that are considered to lack such character. These include mathematical methods, rules and methods for performing mental acts or doing business, presentation of information or computer programs as such. There is a considerable amount of case law to determine whether a claim constitutes one or more of the exclusions.

Methods of treatment of the human or animal body, such as surgery, therapy or diagnostic methods, are also excluded from patentability, but this does not apply to products for use in such methods. Again, whether any given method will be allowable is decided on a case by case basis but there are many previous cases on the matter which provide guidance.

One of the overriding considerations is that a medical practitioner should not be prevented or otherwise impeded from performing his or her medical duties by virtue of the existence of patents. However, it is possible to use a particular form of claim, known as the "first or second medical use" type claim and which can provide protection to the new use of a known composition (see box).

Other exceptions to patentability include those inventions that are considered contrary to "ordre public". Morality issues are often used by third parties to object to what they may view as morally questionable patents, for example, to transgenic animals. However, patents are negative rights that do not confer on the patentee the right to work the invention but only prevent others from doing so. Therefore, if legislation exists, for example, to prevent human cloning, obtaining a patent which may embrace such cloning will not constitute a licence to allow the patentee to conduct research in that area.

\section{Human cloning}

Patents will never be granted in this area in Europe in view of new European Directive amendments to the EPC on the legal protection

\section{FIRST OR SECOND MEDICAL USE}

In the case of a chemical compound or composition that has no previously recognised medical use, it is possible to claim the broad use of the composition in a method of treatment of the human or animal body, thus protecting any medical application of the compound in addition to the specific use exemplified in the patent. Where the compound has a previously recognised medical application, such as for example, in the case of Sildenafil, which was subsequently found to be useful for treating erectile dysfunction, "second medical use" type language can be used which has an accepted format as follows: "use of a composition $\mathrm{X}$ in the manufacture of a medicament for treatment of disease $Y$ ". These claims protect the use of the known composition only for treatment of the specific disease. Nevertheless, any new compound, whether it is intended to be used in a medical context or otherwise, is entitled to broad protection irrespective of the use to which it is put, provided the compound itself is new.

\section{Quote to go in here if you like, will break up the text a bit.Quote to go in here if you like.}

of biotechnical inventions. These rules outline the exceptions to patentability, including processes for cloning human beings, uses of human embryos and processes for modifying the genetic identity that are likely to cause them suffering without any substantial benefit to mankind. The Directive was introduced to harmonise the law in each state of the European Union regarding patentability of inventions in the biotechnology field, although some member states have yet to comply.

\section{Plants and Animals}

Patents on plants or animals are permissible if the technical feasability of the invention is not limited to a particular plant or animal variety by virtue of of the European Directive described above. However, it remains to be seen whether claims to transgenic plants and animals will be upheld in those states that have not yet implemented the Directive.

\section{Gene sequences}

The human body, including the sequence or partial sequence of a gene, is not patentable unless isolated from the human body or produced by means of a technical process. The requirement that the sequence of a gene be isolated or otherwise produced by a technical process is, in fact, somewhat irrelevant because all DNA sequences will generally have to be isolated or otherwise produced by means of a technical process for the sequence to be elucidated. However, it is also stipulated that the industrial application of a gene must be disclosed in the patent application. In other words, it will no longer be sufficient to merely supply the sequence of a new gene for it to be patentable. Its function must also be supplied and how it is to be used. This function must be substantial and credible on the basis of the experimental evidence provided in the application. If the function supplied in the patent application is found to be incorrect, the applicant risks those claims that rely on such function to confer industrial applicability being declared invalid.

Colm Murphy, European Patent Attorney, Boult Wade Tennant, Address line 1, London. e-mail:cmurphy@boult.com doi:10.1038/nrdXXX 